\title{
Social Protection during Disasters: Evidence from the Wenchuan Earthquake
}

\author{
Xiaojiang Hu, Miguel A. Salazar, Qiang Zhang, Qibin Lu and \\ Xiulan Zhang
}

\begin{abstract}
Using evidence from the Wenchuan earthquake (12 May 2008) in China, this article examines the impact of disaster on the functioning of China's social protection system. The article examines the social protection system and the recipients of social protection. It presents four main findings: (1) the impact of the disaster on the social protection system itself was considerable; (2) the system was able to cope fairly successfully with the enormous demands created by the earthquake by a surge of resource utilisation; (3) there was an alarming rate of burnout and possible degradation in capabilities after several months, which may affect the effectiveness of the reconstruction stage, and (4) the demands of the public for perfect equality of treatment has hindered targeting of resources, but also simplified the operation at the relief stage. The article concludes with tentative proposals as to the nature of the institutional resilience expressed in the surge.
\end{abstract}

\section{Introduction}

The Wenchuan earthquake of 12 May 2008 in Sichuan, China, claimed 69,227 lives and left 17,932 people missing. More than 374,000 people were injured. Nearly 90 counties, over 900 towns and more than 9,000 communities suffered severe damage in terms of assets, land, jobs, livelihoods, public facilities, infrastructure, and human lives. Over $13 \mathrm{mn}$ people lost their homes. About $1.15 \mathrm{mn}$ farmers lost their land, and 372,000 urban residents lost their jobs. These staggeringly large numbers make the Wenchuan earthquake the largest natural disaster in the PRC's 60-year history and resulted in the creation of the largest postdisaster social protection schemes in China.

There are a number of studies examining social protection in the context of disasters, and there has been debates about its importance (Subbarao 2005; Del Ninno 2008), as well as suggestions for programme design and lessons regarding particular social protection polices (Lustig 2000). What is missing in this body of research, however, are studies of the effects of disasters on the social protection system itself.
Social protection structures suffer a double blow in a disaster. First, there is the direct damage to resources, in particular personnel and service delivering capacities, and second there is the sudden wave of demand for new forms of social protections from the affected population. This double blow to the social protection institutions often results in an incapacity of existing social protection systems to respond to the needs of the affected population. The problem of a lack of institutional capacity in social protection systems leads us to explore this aspect of the effect of disasters through examining three aspects: organisational disaster preparedness, institutional robustness and operational resilience.

In a disaster, government agencies are often the lifeline for communities and the last resort for most vulnerable people. Thus, the failure of government institutions causes the population additional distress and suffering. Disasters mercilessly expose institutional vulnerabilities. For example, after Hurricane Katrina and other Mexican Gulf region disasters, many US government agencies were made aware that 


\begin{tabular}{|c|c|c|}
\hline \multicolumn{2}{|c|}{ Damages due to the Wenchuan earthquake } & \multirow{2}{*}{$\begin{array}{l}\text { (\%) } \\
74.2\end{array}$} \\
\hline Hardware & Office buildings & \\
\hline & Office furniture & 53.0 \\
\hline & Archived files and data & 15.6 \\
\hline & Official stamps and documents & 7.1 \\
\hline & Vehicles and equipment & 18.4 \\
\hline & Building damage resulting in very poor physical working conditions & 46.4 \\
\hline \multirow[t]{4}{*}{ Personnel } & New staff not up to the task & 6.6 \\
\hline & System personnel injured & 8.0 \\
\hline & Family members injured & 13.2 \\
\hline & Family members died or missing & 6.7 \\
\hline
\end{tabular}

relying on a single form of communication leaves the government itself vulnerable to breakdowns (Rutzick 2007).

When organisations experience disaster impacts, 'cracks' may appear in service delivery systems (Tausig 1987). Different types of cracks can be identified in organisations' service networks depending on the nature of the organisational structure, the degree of impact, and the level of preparedness (Gillespie and Murty 1994). Identifying and classifying the underlying weaknesses revealed by those cracks are thus essential for resuming normal functioning (Perrow 1994). Equally, identifying points of special resilience can help determine the best way to prepare these institutions for catastrophe.

In this article, we examine the social protection system in the aftermath of the Wenchuan earthquake from the perspectives of institutional vulnerability and resilience. Based on household surveys conducted two months after the earthquake, and surveys of officials six to eight months after the earthquake, the article examines both the social protection system itself (system design and local government agencies and officials) and the recipients of the social protection (people affected by the earthquake).

\subsection{Data sources}

This article is based on data collected by our field teams in the affected areas (mostly Mianyang county). The main collecting instruments were: a household survey, a survey of officials and qualitative data collected during a number of field visits. Document reviews of government instruments were carried out both in Sichuan and back in Beijing.

The household survey was conducted between 20 June and 10 July 2008 in Mianyang, the hardest-hit city in the Wenchuan earthquake. By this time, all people in Mianyang city had been evacuated from their homes and had been settled in temporary camps. We randomly selected five camps. Then, from every two tents, we sampled one household to interview. Where a tent housed several households, we chose the one where the household head was present. The total number of households interviewed was 2,003, and we obtained information for each member, giving a total individual sample size of 7,407.

A survey of officials was also carried out. Mianyang city government decided to train its officials in all levels of governments and all agencies in order to build capacity in managing recovery and redevelopment policies. Around 2,060 officials were trained in the City Public Administrative College from 6 December 2008 to 26 February 2009. The training covered all those with the administrative ranking of township head or above in Mianyang city. We used this opportunity to distribute the questionnaire to each official, receiving 1,241 responses.

Moreover, we undertook surveys and interviews five days after the earthquake, in the quake areas, and were also involved in planning policy 


\begin{tabular}{|c|c|c|c|c|c|c|c|}
\hline \multirow[t]{2}{*}{ Type of assistance } & \multirow{2}{*}{$\begin{array}{l}\text { Received } \\
\text { (\%) }\end{array}$} & \multicolumn{6}{|c|}{ Provider (\%) } \\
\hline & & $\begin{array}{l}\text { Relatives or } \\
\text { friends }\end{array}$ & $\begin{array}{l}\text { Local } \\
\text { officials }\end{array}$ & $\begin{array}{l}\text { Government } \\
\text { agencies }\end{array}$ & Volunteers & Army & NGOs \\
\hline Rescue and evacuation & 34.0 & 9.7 & 4.0 & 6.6 & 8.1 & 19.0 & 3.3 \\
\hline Food and water & 92.7 & 5.0 & 19.0 & 61.1 & 17.9 & 5.3 & 6.8 \\
\hline Other necessities & 80.9 & 4.7 & 16.0 & 52.0 & 16.4 & 3.8 & 7.3 \\
\hline Medical services/medicines & 81.2 & 1.3 & 15.2 & 53.8 & 14.4 & 3.9 & 8.1 \\
\hline Cash & 70.4 & 3.4 & 7.3 & 45.6 & 3.8 & 0.3 & 2.3 \\
\hline Shelter & 32.1 & 7.1 & 5.0 & 17.6 & 2.2 & 1.4 & 1.1 \\
\hline Building tents/shelters & 57.5 & 5.6 & 6.7 & 33.0 & 6.2 & 8.8 & 4.0 \\
\hline Childcare/tutoring & 13.9 & 0.4 & 0.3 & 2.6 & 8.6 & 0.6 & 2.5 \\
\hline Counselling & 27.3 & 6.9 & 3.2 & 3.9 & 16.0 & 0.7 & 0.9 \\
\hline Books & 16.9 & 0.0 & 1.8 & 4.9 & 8.8 & 0.3 & 1.7 \\
\hline Other assistance & 6.6 & 1.0 & 1.3 & 1.2 & 2.9 & 0.4 & 0.7 \\
\hline
\end{tabular}

research for the National Disaster Reduction Commission during and after the earthquake. Key policy documents, especially those related to social protection after the Wenchuan earthquake, are discussed.

The survey data was tabulated and analysed using standard statistical packages. The interviews were fully transcribed and analysed using both quantitative and qualitative methods. All tables in this article were produced using those datasets.

\section{Impact of the disaster of the social protection system}

2.1 The SP system suffered extensive damage

Beichuan, the county hardest hit by the earthquake, suffered grave loss of life and government capacity. Of the 3,441 government personnel, 568 died and 172 were severely disabled in the earthquake, giving a total casualty rate of 21.5 per cent. In addition, of the surviving cadres, 36.2 per cent had close family members die in the earthquake.

In Mianyang city, where the survey of officials was carried out, capacity was relatively less damaged than Beichuan. Of the cadres surveyed, 8 per cent suffered injures; 13.2 per cent of their family members were injured and 6.7 per cent had family members who had died or were declared missing. The loss of personnel and facilities, plus the inevitable organisational disruption of the disaster presented a great challenge to the functioning of the social protection system in the period immediately after the disaster. Another challenge to be faced were the bad working conditions most officials had to negotiate during the emergency, which in turn greatly increased the physical strain on the officials. The various forms of damage suffered by the social protection institutions as the result of the earthquake are shown in Table 1.

\subsection{Most affected people received social protection promptly}

Overall, the response to the earthquake was effective, judging by the opinion of the people affected. The mobilisation of resources was speedy and, despite logistical difficulties caused by the terrain, emergency supplies reached the affected populations fairly quickly. Overall, the early relief effort was more than sufficient to avoid a 'secondary catastrophe' and undue hardship on the survivors. Using our data, we analysed the type of assistance the affected population received (Table 2 ).

Our findings show considerable variation in the kind and amount of help received. During the rescue and evacuation period, relatives, friends and the army provided the most help, a common 


\begin{tabular}{lll}
\hline Table 3 Survivors' living conditions two months & & \\
\hline Living conditions & & (\%) \\
\hline Enough food & Yes & 99.0 \\
& No & 1.0 \\
Meat available & Daily & 23.8 \\
& $4-5$ times per week & 5.5 \\
& 2-3 times per week & 22.8 \\
& Once a week & 30.8 \\
Electricity & Less than once a week or none & 17.1 \\
Safe drinking water & Yes & 68.9 \\
& No & 31.1 \\
Safe & 92.9 \\
Satisfaction with current conditions & Not safe & 4.6 \\
& Unknown & 2.5 \\
& Very satisfied & 11.1 \\
& Satisfied & 75.1 \\
Not very satisfied & 11.6 \\
& Very unsatisfied & 2.1 \\
\hline
\end{tabular}

pattern in early disaster response. Government agencies were the main providers of food, water, living necessities, medical services, medicines and shelter. Volunteers were expected to play an important role in social protection provision, especially in providing food, water, living necessities, medical services, medicine, counselling, books, childcare and tutoring, yet local NGOs (which include organisations engaged in advocacy on environmental matters, child protection and other social causes) are still perceived to have played a relatively minor role in disaster assistance.

The household surveys conducted two months after the earthquake in the temporary shelters indicated that the social protection outcomes of the survivors were generally good, given the scale of the disaster. Some 99 per cent said they had enough food to eat, most of them had meat in their meals, and nearly 70 per cent of the shelters had electricity; 92.9 per cent of the affected had access to safe drinking water; 86.2 per cent of the surveyed people said they were very satisfied or satisfied with their current living conditions. Table 3 presents these findings.
3 Why the system worked despite extensive damage: elements of resilience 3.1 Solid macro-level institutions and planning is crucial in post-disaster social protection at local level

China's pre-disaster emergency social protection system, as established in the relevant legal instruments, is based around a centralised coordinating body for social protection in disasters. The Ministry of Civil Affairs is responsible for formulating national disaster response polices, strategies and programmes; for coordinating with central government departments; and for providing guidance to local governments on disaster mitigation and relief activities. However, most of the line responsibilities lie with local authorities and provincial governments.

Shortly before the earthquake, on 5 August 2007, China's State Council had formally issued the 11 th National Integrated Disaster Response Five Year Plan. The goal was to establish a unified management structure that would coordinate all levels of government during the rescue stage of an emergency. It also paid attention to strengthening the network for central and local material reserves for disaster assistance and the 
Table 4 Coping with the sudden increase in demand for social protection

$\begin{array}{lc}\text { Increased workload } & 64.1 \\ \text { Increased responsibilities } & 67.8 \\ \text { Responsibilities during the first month after the disaster } & \\ \text { Statistical information collection and reporting } & 49.8 \\ \text { Rescue and transferring injured } & 23.1 \\ \text { Evacuation and temporary settlement of the survivors } & 51.6 \\ \text { Relief materials and fund allocation and management } & 46.5 \\ \text { Building temporary shelters } & 22.4 \\ \text { Managing temporary shelters } & 13.3 \\ \text { Clearing of dead bodies and ruins } & 6.4 \\ \text { Sanitation and epidemic control } & 18.5 \\ \text { Increased working hours (in extra hours) } & \\ \text { Before quake } & 8.2 \\ \text { One month after } & 13.3 \\ \text { Current } & 9.3 \\ \text { Changed job or promoted to new positions } & 16.7\end{array}$

production of equipment for disaster mitigation and assistance, and to improving mechanisms to mobilise the local population and the support of other unaffected regions. Most notably, for the first time, the plan made mention of the Red Cross non-governmental and grassroots organisations, and formally acknowledged that these non-government actors should have responsibility for disaster prevention, early postdisaster emergency rescue, disaster relief donations, medical aid, epidemic prevention, rehabilitation and reconstruction, and postdisaster psychosocial support.

Following the earthquake, the state council passed a number of measures detailing courses of action for relief and early reconstruction (see Appendix) that provided the macrostructure of the reconstruction of the social protection system and its expansion as a mechanism to help the wider reconstruction of the affected region. Especially successful were the policies passed in late May 2008 that included provision of a stipend of 300 yuan and $0.5 \mathrm{~kg}$ of grain per month for each person in the affected area, an emergency stipend that was to last three months. Soon after, a policy was issued to target the assistance and provide continuing relief to those eligible (as opposed to the universal coverage of the original stipend) at a reduced level of 200 yuan per month for the next three months. These stipends were simple to administer, easy for recipients to understand, and provided immediate relief to the affected. (A list of key policies issued after the Wenchuan earthquake is provided in the Appendix.)

\subsection{Model resilience in the social protection system}

Besides the damage to its capabilities, the sudden increase in demand put great pressure on the social protection system. These combined pressures forced institutions to reorganise and forced officials to make exceptional efforts to ensure the delivery of social protection to needy people. The strategies used shed some light on the characteristics of institutional resilience in a disaster.

Officials at all levels performed well during the emergency. During the critical first month, surviving personnel had to take on not only a massively increased workload, but a great variety of emergency tasks for which they were not formally trained or experienced. Tasks such as collecting and reporting statistics of deaths, injuries and damages (the continuous demand for information, and the pressure this put on personnel was a common theme in the interviews), rescuing and transferring the injured, evacuating and settling the survivors, building and managing temporary shelters, helping sanitation and epidemic control and clearing of dead bodies and ruins. Table 4 summarises the ways in which local authorities 
responded to the new demands, and the obligations they undertook.

This flexibility of task management points to one significant factor. Operational resilience often lies in the ability of actors to take on unfamiliar tasks and improvise ways to reuse surviving resources. In the interviews, a common theme was the value of modelling. Familiarity with the overall mechanisms of social protection administration, in particular the new protocols for identifying needs and distributing assistance in orderly ways were critical for officials dealing with unexpected demands and new responsibilities, such as allocating building materials for temporary shelter. This can be called 'model resilience', in which broad, general practices can be applied to changing situations.

\subsection{Surge and burnout: overloading the social protection system}

While the social protection system managed to cope with the challenges of the disaster fairly well, it did so at the cost of straining its capabilities to the maximum. This overstraining means that the social protection system is borrowing from the future to deal with the present. Success in relief may come at a price that will be felt during reconstruction.

The main response to the extreme stress that the disaster put on the system was an increase in the usage of existing resources to the maximum, in particular human resources. This 'surge' of effort was not sustainable, and created a significant 'burnout' problem with personnel. Table 5 summarises the pressure on local officials and the impact on their mental and physical health. Using the Center for Epidemiologic Studies Depression Scale (CESD) (data collected by our team during the cadre interviews), the average score of the officials was 12.9 six months after the earthquake. At this stage, 20.1 per cent of them had a score over 20, which indicates severe depression and 12.1 per cent had scores between 16 and 19, indicating moderate depression. On average, the officials each reported 1.9 health symptoms, an indicator of general stress on their health.

There was a significant change in self-reported health status. Those who reported themselves in excellent health dropped from 28.4 per cent to 8.9 per cent, and those in very good health also decreased from 36.8 per cent before the earthquake to 25.7 per cent after it. Those who reported poor and fair health status increased significantly, from 5.3 to 21.6 per cent. Over 30 per cent said their health problems were severe, although more than half did not seek healthcare, with the main reason being lack of time to go to hospital. The pressure also resulted in increased consumption of alcohol and tobacco: before the disaster, 78.8 per cent were daily smokers, but this percentage had increased to 87 per cent six months after the quake. Similar results on alcohol use have been reported, although we do not yet have hard data.

The burnout problem can leave the system vulnerable after the initial relief stage is over. This can affect the critical early reconstruction effort. The exact shape of the 'overload' curve varies by locale. In Mianyang, it seems there was a trough of capability around six months after the disaster struck. This is also around the time when relief becomes long-term reconstruction and restoration, and social protection must shift emphasis to longterm needs rather than the acute demands of the disaster. The loss of capability, therefore, probably affects this transition.

\section{Public demands for assistance and their effect on official response: equality and the focus on equal treatment}

A dominant theme found in the interviews with both the affected people and the officials is an overarching concern with fairness of treatment. This concern with fairness was expressed with a very strong emphasis on equality, understood as exact sameness of treatment by social protection institutions.

It will be fine if no one receives assistance, but if someone else has it, I must have it.

(Quote from an interview with an individual survivor in July 2008)

\footnotetext{
If you cannot provide enough relief to everyone, it is better not to allocate anything to my village. I cannot decide who should be eligible, and if I cannot distribute the relief equally, I am afraid it will cause social unrest.

(Quote from an interview with a village official in August 2008)
}

Table 6 presents the perception of the nature of the allocation of disaster assistance from the 


\begin{tabular}{|c|c|c|}
\hline \multicolumn{3}{|l|}{ Mental health } \\
\hline \multicolumn{3}{|l|}{ CESD (\%) } \\
\hline$<16$ & & 67.9 \\
\hline $16-19$ & & 12.1 \\
\hline$\geq 20$ & & 20.1 \\
\hline Average score & & 12.9 \\
\hline \multicolumn{3}{|l|}{ Symptoms (\%) } \\
\hline Chest pain & & 14.3 \\
\hline Stomach pain & & 9.9 \\
\hline Diarrhoea & & 11.2 \\
\hline Headache & & 36.6 \\
\hline Serious injury & & 0.7 \\
\hline Non-serious injury & & 3.9 \\
\hline Fever & & 4.9 \\
\hline Cough, sore throat & & 45.3 \\
\hline Palpitation & & 44.8 \\
\hline Other & & 17.2 \\
\hline Total score & & 1.9 \\
\hline Self-reported health status (\%) & Before & After \\
\hline Excellent & 28.4 & 8.9 \\
\hline Very good & 36.8 & 25.7 \\
\hline Good & 29.5 & 43.9 \\
\hline Fair & 3.9 & 17.2 \\
\hline Poor & 1.4 & 4.4 \\
\hline \multicolumn{3}{|c|}{ Self-assessment of current health problems (\%) } \\
\hline Very serious & & 1.7 \\
\hline Relative serious & & 10.1 \\
\hline Serious & & 27.7 \\
\hline Not serious & & 42.5 \\
\hline Hard to say & & 17.9 \\
\hline \multicolumn{3}{|l|}{ Treatment when sick (\%) } \\
\hline Hospitalised & & 4.1 \\
\hline Outpatient clinic treated & & 21.2 \\
\hline Family/friend treated & & 3.7 \\
\hline Bought drugs & & 56.3 \\
\hline Not treated & & 14.8 \\
\hline \multicolumn{3}{|l|}{ Reason for not seeking treatment (\%) } \\
\hline Not serious & & 31.2 \\
\hline Financial difficulties & & 6.7 \\
\hline No time & & 43.9 \\
\hline Inconvenient transport & & 0.7 \\
\hline Long waiting line in the hospitals & & 3.3 \\
\hline Don't like hospitals & & 9.3 \\
\hline Other & & 4.9 \\
\hline Behaviour health: smoking (\%) & Before & After \\
\hline Occasionally & 21.2 & 13.0 \\
\hline Daily & 78.8 & 87.0 \\
\hline
\end{tabular}


Table 6 Allocation of the relief materials and funds (\%)

\begin{tabular}{lll}
\hline & People & Cadres \\
\hline Each household about the same & 25.0 & 20.0 \\
Bigger households received more & 53.0 & 26.7 \\
Households which suffered greater losses received more & 10.4 & 44.7 \\
Poor received more & 1.9 & 4.1 \\
Rich received more & 0.2 & 0.5 \\
Powerful received more & 2.2 & 0.9 \\
Households with more connections received more & 4.5 & 0.6 \\
Those who complained more got more & 0.4 & 2.1 \\
Those who came early received more & 2.5 & 0.6
\end{tabular}

officials' and recipients' perspectives. There was a marked difference in the way both sides perceived the allocation of resources. Over 50 per cent of recipients believed that more relief materials and funds were allocated to the bigger households; the officials thought they had allocated the relief materials and fund to the households which had suffered the biggest losses. Officials were twice as likely as recipients to say that they had allocated more assistance to the poor. Furthermore, recipients believed that those who were powerful, with connections, and those who came early got more. Interestingly the officials believed that it was those who complained the loudest that had been likely to receive more, but recipients did not believe this.

These differences in perceptions of allocative principles (targeted vs. universally equal) affected how people viewed the fairness of the disaster assistance. Table 7 presents these findings.

The overwhelming majority of officials believed that the distribution of relief, fund allocation process and the outcomes were fair or relatively fair. The affected people generally agreed on the fairness of the allocation, but a significant minority felt that the system was not fair. Table 7 indicates that both officials and recipients put great emphasis on equality of treatment by social protection institutions.

While most of those affected perceived the process of allocation as basically fair, the emphasis on identical treatment influenced the distribution of assistance in potentially damaging ways. This emphasis on equality probably derived from the perception that any deviation would result not from rational criteria or impartial need assessment. Instead, the expectation was that unequal assistance would result from influence peddling. This belief was so strong that it influenced perceptions of the fairness of the process of allocation, and in turn, affected the behaviour of the relief suppliers, who avoided conflict by attempting to preserve a sense of fairness-as-equality.

\section{Conclusions}

\subsection{Key elements of resilience in social protection}

This article has used the Wenchuan earthquake as a case for the damage suffered by, and the resilience of, social protection systems and providers during disasters. The analysis of the data is still ongoing, but we have identified several main areas of interest involving the resilience, fragility and continued functioning of social protection structures during disaster situations.

First, the social protection system itself will also suffer from damages in disasters. This calls for extra planning and recovery strategies for the institutions themselves if they are to restore enough capacity with sufficient speed. The social protection system can cope in a short burst, but it does so by overstraining to provide basic requirements when most needed.

At a macro-level, the study supports the importance of an actionable disaster response plan, quick policy responses and innovative approaches in both financing and delivery of 
Table 7 Equity concerns over disaster assistance. Were the relief materials and funds distributed fairly? (\%)

\begin{tabular}{llll}
\hline & Officials' view of the process & Officials' view on the outcome & Recipients' view of the outcome \\
\hline Fair & 23.3 & 17.9 & 34.5 \\
Relatively fair & 73.0 & 76.5 & 45.2 \\
Not fair & 3.8 & 5.7 & 20.3 \\
\hline
\end{tabular}

social protection. The centralised but layered nature of the Chinese state creates complex issues of coordination and unclear chains of command.

How the structure of the pre-disaster social protection system influences its resilience in the event of a disaster is less clear. It seems apparent from the responses that a wide general understanding of the functioning of social protection processes allowed personnel to take on new tasks and develop new skills as required, something that seems to have helped create systemic resilience. These daunting tasks of social protection after earthquakes can be managed by reallocating local government staff and officials. Even severely damaged social protection institutions restored functionality in a very short period by intensifying the use of surviving resources. However, this 'burst' overstresses the local system in the long run, as human resources become over-exhausted and existing organisational structures become overextended and frayed. This can result in an 'aftershock' dip in functionality, or even near-systemic failure, several months after the initial event. 